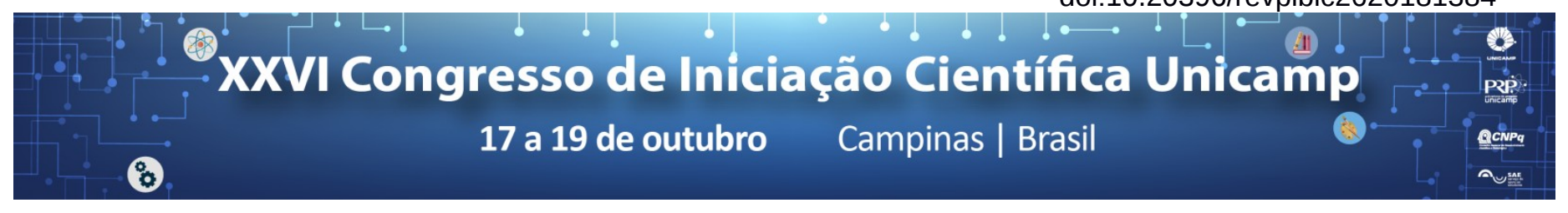

\title{
Algoritmos de Sequenciamento de Tarefas e uma Aplicação ao Problema de Sequenciamento de Aviões de uma Companhia Aérea entre Origens e Destinos
}

\author{
William H. Shie*, Priscila B. Rampazzo
}

\begin{abstract}
Resumo
O problema de alocação de frotas, conhecido como Fleet Assignment, consiste em alocar o tipo de aeronave que percorrerá cada percurso, conhecendo os percursos, a quantidade de cada tipo de aeronave e as características de ambos. O objetivo deste projeto foi propor e implementar um Algoritmo Genético para tratar este problema. Este problema pode ser modelado como um problema de Scheduling, que trata da alocação de recursos para processamento de tarefas; modelagem que se encaixa na classe de problemas NP-difícil, o que justifica a metologia heurística escolhida para resolução. Os Algoritmos Genéticos, apesar de não garantir a solução ótima, garante uma solução de qualidade com baixo custo computacional.
\end{abstract}

\section{Palavras-chave:}

Sequenciamento de Tarefas, Algoritmos, Fleet Schedule

\section{Introdução}

O Problema de Sequenciamento de Aviões de uma Companhia Aérea entre Origens e Destinos (Fleet Assignment) pode ser definido da seguinte maneira (Hanif et. al., 2016): Dado um conjunto de segmentos de vôos com distâncias conhecidas, encontre o sequenciamento dos diferentes tipos de aeronaves que otimize um objetivo, de maneira que o balanço de fluxo de aeronaves seja conservado para cada aeroporto (todos os vôos que chegam, devem partir) e apenas o número disponível de aeronaves de cada tipo seja utilizado. Este problema pode ser modelado como um Problema de Scheduling. Problemas de Scheduling pertencem à classe NP, sendo considerados de difícil resolução. Metaheurísticas Evolutivas têm sido aplicadas na resolução de problemas NP-difícil. O Algoritmo Genético (AG) é um método da classe das Metaheurísticas Evolutivas, resultante da aplicação iterativa de técnicas heurísticas, baseadas na seguinte sequência de passos: inicialização de uma população de soluções (indivíduos); realização de recombinação entre indivíduos para obtenção de novas soluções (crossover); mutação (promovendo variabilidade), competição e seleção dos indivíduos mais aptos. Este processo torna os AG capazes de promover a busca por soluções em um enorme espaço de possibilidades, de maneira muito flexível (Knowles, et al., 2008).

\section{Resultados e Discussão}

Analisou-se o problema de alocação de frotas (Fleet Assignment), com o intuito de obter uma alocação de diferentes tipos de aeronaves aos percursos conhecidos. Foram realizados testes baseados em dados reais de cidades brasileiras e de uma companhia aérea. Os parâmetros do problema são: conjunto de aeroportos, conjunto de percursos e conjunto de aeronaves. Buscouse, sempre que possível, utilizar-se de dados fornecidos, estimando outros quando estes não eram acessíveis. Com os dados de entrada prontos, foi proposto e implementado um AG para tratamento do problema. Os indivíduos foram gerados aleatoriamente satisfazendo restrições de cobertura (uma aeronave deve cobrir pelo menos duas cidades; uma cidade pode ser coberta por mais de uma aeronave), balanceamento e disponibilidade. As funções-objetivo (ou funções que medem a aptidão de um indivíduo) consideradas nos testes foram: minimização do maior tempo de viagem de uma aeronave, com o intuito de balancear o tempo gasto entre todo o conjunto; e a minimização do custo total de toda a operação. O AG foi implementado em linguagem C.

\section{Conclusões}

O problema de alocação de frotas tem semelhanças com o Problema de Sequenciamento de Tarefas em Máquinas Paralelas uniformes, onde máquinas (aeronaves) devem processar tarefas (segmentos de vôo) e a velocidade das máquinas são diferentes. Por isso, na primeira etapa do projeto foram analisados dois modelos de Scheduling: de máquinas paralelas idênticas e de máquinas paralelas uniformes. Os resultados desta etapa foram divulgados em um artigo publicado no ERPO 2018 (Passos et. al., 2018). $\mathrm{Na}$ segunda etapa, até o momento, foi possível observar um bom resultado do AG e acredita-se que abordagens heurísticas podem ganhar mais espaço no problema de alocação de frotas, principalmente em situações com grande número de percursos, maior número de restrições, e considerando outras regras do transporte aéreo, com o intuito de representar modelos mais realistas e mais complexos. Os resultados do AG foram comparados com a solução obtida por um solver de Programação Linear Inteira (CPLEX).

Hanif D. Sherali, Ebru K. Bish, Xiaomei Zhu, Airline fleet assignment concepts, models, and algorithms, European Journal of Operational Research, Volume 172, Issue 1, 2006, Pages 1-30.

Knowles, J.; Corne, D.; Deb, K. Multiobjective Problem Solving from Nature: From Concepts to Applications. 1. Berlin: Springer-Verlag, 2008.

Passos, G.; Pennone, M. D.; Mendonça, R. G. R.; Shie, W. H.; Rampazzo, P. C. B. Algoritmos para o Sequenciamento de Tarefas em Máquinas Paralelas, Anais do III Encontro Regional de Pesquisa Operacional - ERPO, 2018. url: https://drive.google.com/file/d/1QJmJ7bbeW-yypLjXJ5aYd9EytudNzzcK/view

*Os autores agradecem ao PIBIC/CNPq pelo apoio financeiro e incentivo. 